\title{
Planning bridges the intention-behaviour gap: Age makes a difference and strategy use explains why
}

\author{
Tabea Reuter ${ }^{\text {** }}$, Jochen P. Ziegelmann ${ }^{\mathrm{a}}$, Amelie U. Wiedemann ${ }^{\mathrm{a}}$, \\ Sonia Lippke ${ }^{a}$, Benjamin Schüz ${ }^{b}$ and Leona S. Aiken ${ }^{c}$ \\ "Department of Health Psychology, Freie Universitaet Berlin, Habelschwerdter Allee 45, \\ Berlin 14195, Germany; "German Centre of Gerontology, Manfred-von-Richthofen- \\ Strasse 2, Berlin 12101, Germany; ' Department of Psychology, Arizona State University, \\ Box 871104, Tempe, AZ 85287-1104, USA
}

\begin{abstract}
Objective: This study examines age-differential association patterns between intentions, planning and physical activity in young and middleaged individuals. The effectiveness of planning to bridge the intentionbehaviour gap is assumed to increase with advancing age. We explore the use of behaviour change strategies that include selection, optimisation and compensation (SOC) as underlying mechanisms for age differences. Methods: In $N=265$ employees of a national railway company (aged 19-64 years), intentions, planning, SOC strategy use and physical activity were assessed at baseline (Time 1) and again 1 month later (Time 2). Hypotheses were tested in two different path models. Results: Age moderates the extent to which planning mediates the intention-behaviour relation due to an increasing strength of the planning behaviour link. As a possible psychological mechanism for these age differences, we identified SOC strategy use as a mediator of the age by planning interaction effect on physical activity. Conclusion: These findings suggest differential mechanisms in behaviour regulation in young and middleaged individuals.
\end{abstract}

Keywords: self-regulation; planning; selection, optimisation and compensation (SOC); moderation; mediation; health behaviour change

\section{Introduction}

Leading a healthy lifestyle may reduce the probability of pathological aging and is therefore seen as a general principle for successful development (Baltes \& Baltes, 1990). Especially early in life, the accumulation of health resources (e.g. by means of health behaviours) is seen as an important foundation for subsequent life span development and old age (Baltes \& Smith, 2003). Promoting healthy lifestyle changes may hence serve to maintain employability and productivity in the face of an aging workforce. The present study aims to explore the processes that promote health behaviours in young and middle adulthood in a working population. The study focuses on regular physical activity, which is associated with health benefits,

*Corresponding author. Email: tabea.reuter@fu-berlin.de 
irrespective of age (McAuley \& Rudolf, 1995) and which helps to prevent the two leading causes of mortality, cardiovascular disease and cancer ( $\mathrm{Hu}$ et al., 2005). According to Blair and LaMonte (2006) a sedentary lifestyle and low cardiorespiratory fitness are among the strongest predictors of premature mortality. Leisure time phyiscal activity is associated with a decreased risk of poor physical functioning later in life of both white-collar and blue-collar workers (Leino-Arjas, Solovieva, Riihimäki, Kirjonen, \& Telama, 2004) and may prevent work-related musculuskeletal disorders in individuals with low work-related physical activity, fixed body positions or repetitive movements (van Eijsden-Besseling, Staal, van Attekum, de Bie, \& van den Heuvel, 2008).

However, with increasing age, physical activity levels decline (Verbrugge, Gruber-Baldini, \& Fozard, 1996) independent of cohort effects (Bijnen, Feskens, Caspersen, Mosterd, \& Kromhout, 1998). Little research has identified the determinants that maintain physical activity in middle adulthood as compared to young adulthood. Nevertheless, research suggests that the potential for effective preventive measures extends to middle and old adulthood (e.g. Aldwin, Spiro, Park, Birren, \& Schaie, 2006). Thus, integrating a developmental perspective into health behaviour theory and health behaviour research is a strong research desideratum, which allows examining the value of factors affecting health behaviours across different age groups (Prohaska \& Clark, 1997).

\section{Determinants of health behaviour change across the life span}

Current health behaviour theories assume that health behaviour change is a selfregulatory process that consists of a motivation phase of goal setting and a volition phase of goal pursuit (e.g. Abraham, Sheeran, \& Johnston, 1998; Heckhausen \& Gollwitzer, 1987). Volitional factors can help to bridge the so-called 'intentionbehaviour gap' (Sheeran, 2002), i.e. the phenomenon that people do not fully act upon their intentions. Thus, a major challenge for models of behaviour change is unravelling the mechanisms that operate between intention and actual behaviour. Empirical evidence suggests that detailed planning and life-span related strategy use in terms of selection, optimisation and compensation (SOC) are important predictors of health behaviour change (Gollwitzer \& Oettingen, 1998; Schwarzer, Luszczynska, Ziegelmann, Scholz, \& Lippke, 2008; Ziegelmann, Lippke, \& Schwarzer, 2006a). The present study attempts to shed light on the role of planning as a mediator of the intention-behaviour relation. Further, we explored the extent to which age modifies the linkage between planning and behaviour and the extent to which constructs from life-span psychology (SOC strategy use) explains given age-related differences.

\section{The mediation of the intention-behaviour relation through planning}

Planning plays a major role in the volition phase and is assumed to facilitate goal pursuit by linking behavioural responses to specific situations. Planning can be subdivided into two facets: action planning and coping planning. In the process of action planning (i.e. implementation intention; Gollwitzer, 1999) an action sequence is linked to specific parameters of a situation in terms of 'when', 'where' and 'how' to perform a behaviour (e.g. Armitage, 2007; Sniehotta, Scholz, \& Schwarzer, 2005). This process can also be considered as a mental simulation of behaviour in crucial 
key situations (Pham \& Taylor, 1999). Holding such a mental representation in a critical situation is assumed to lead to an immediate and efficient behavioural response without conscious awareness. Increased information processing (e.g. accessibility and strength of cue-response links) has been identified as an underlying working mechanism of implementation intentions (Webb \& Sheeran, 2007). Selfgenerated implementation intentions predict physical activity over and above goal intentions for an extensive period of time (up to 12 months; Ziegelmann, Luszczynska, Lippke, \& Schwarzer, 2007).

Coping planning, on the other hand, refers to the anticipation of barriers (e.g. distractions, temptations or conflicting habits) and the generation of behavioural (or cognitive) responses to overcome them (e.g. Sniehotta et al., 2005). An action plan specifies the details of action implementation (the when, where and how), whereas a coping plan specifies how to cope with anticipated barriers. Both facets of planning jointly work together in concert and thus can be considered in combination. Intervention studies show that individuals who engage in a combination of action planning and coping planning display greater changes in behaviour than individuals who focus on action plans alone (Sniehotta, Scholz, \& Schwarzer, 2006; Ziegelmann et al., 2006a).

Planning is hypothesised to mediate the intention-behaviour relation (e.g. Schwarzer et al., 2008) and is the critical psychological process through which behavioural intentions are translated into behaviour. Individuals with higher intentions are more likely to plan when, where and how to act; their plans help them translate their intentions in behaviour. This mediating effect of planning between intention and behaviour has been demonstrated in studies in which planning was experimentally induced (e.g. Reuter, Ziegelmann, Wiedemann, \& Lippke, 2008), as well as in observational studies in which planning was measured psychometrically (e.g. Norman \& Conner, 2005).

\section{Does age make a difference?}

According to Prohaska and Clark (1997, p. 30) the "validity of theoretical constructs that comprise models of health behaviour change has not been well documented across all segments of the life span'. For both theory development and the design of age-sensitive interventions, it is important to consider age-associated changes in selfregulation of health behaviours. As the processes that underlie the maintenance of health behaviour may vary with age, the present study explores the factors that underlie the maintenance of physical activity across age. We assume that intention to engage in physical activity predicts both subsequent planning and physical activity, whereas planning predicts physical activity. Furthermore, we predict that the strength of the association between planning and physical activity will increase with age; this is represented by an interaction between age and planning. Stated differently, we propose that age modifies (i.e. moderates) the planning-activity link.

\section{Possible explanation for age-differential effects}

As age cannot be referred to as a 'causal' variable (Schaie, 1988), possible underlying mechanisms of the age-differential effect need to be examined. The model of SOC (P. Baltes \& M. Baltes, 1990) provides a theoretical framework for the development 
of self-regulation (i.e. goal selection and goal pursuit) across the lifespan. The SOC model forms the basis of our expectation that the strength of association between planning and physical activity will increase in age. The SOC model yields four adaptive strategies for self-regulation: (1) Elective selection (i.e. developing and committing to a hierarchy of personal goals), (2) Optimisation (i.e. engaging in goaldirected actions and means), (3) Loss-based selection (i.e. changing the goal or the goal system in response to loss in goal-relevant means) and (4) Compensation (i.e. acquiring and using alternative means in response to loss in goal-relevant means). In an action-theoretical framework, SOC is seen as a dynamic system that operates as an integrated ensemble of the processes of SOC (Freund \& Baltes, 2000). While planning can be seen as aiming at achieving a specific goal (Das, Kar, \& Parrila, 1996), we conceptualise SOC strategy use to guide behaviour at the operational level (Ziegelmann \& Lippke, 2007). Thus, self-reported planning exhibits to what extent an individual plans to perform a behaviour in a given context (e.g. 'I have already precisely planned how I can be physically active even in the face of difficulties and barriers'). Self-reported SOC strategy use, on the other hand, gives insights how people actually go about to do this (e.g. 'When it is getting more difficult to lead a healthy lifestyle, $I$ increase my efforts even more'). Stated differently, SOC can be seen as the driving force behind the execution of plans. The extent to which SOC strategies are incorporated into planning activities predicts behaviour over time. Ziegelmann et al. (2006a) reported that the extent to which SOC strategies were incorporated into the exercise plans of orthopaedic rehabilitiation clients predicted their exercise maintenance for 6 months following rehabilitation treatment.

Taking a life span view, Freund and Baltes (2002) argue that individuals acquire and refine their knowledge and use SOC-related strategies with increasing age. For instance, compared to young adults, middle-aged individuals have made more experience with barriers to behaviour and experience losses in their respective life courses. Thus, coping planning as a way of overcoming barriers to action might be more effective in translating intentions into behaviour in middle-aged adults who make use of compensation strategies (Freund \& Baltes, 2002). For instance, when a temporary foot pain does not allow going running, swimming as a compensatory alternative of physical activity can help to maintain one's exercise level. If compensatory means are no longer available to achieve a given exercise goal, new standards can be adopted that can be achieved with the available resources (lossbased selection).

Thus, the close orchestration of planning and SOC strategies should foster the planning-behaviour link in middle-aged as compared to younger adults, because these middle-aged adults have more experience in terms of goal achievement. The second focus of the present study therefore is to examine whether an increase in the strength of association between planning and actual physicial activity with increasing age (i.e. the age by planning interaction) can be explained by an increase in use of SOC strategies. Put another way, we can ask whether the effect of the positive interaction between age and planning on physical activity is attributable to (i.e. mediated by) increased use of SOC strategies. For instance, we assume that a middleaged individual is more likely than a younger individual to use SOC strategy to translate plans into action.

An examination of these hypothesised processes in the domain of physical activity maintenance requires a population with a wide age range in which a portion of individuals maintain their physical activity. Only then it is possible to examine the 
processes that underlie physical activity maintenance across different age groups. A population in which physical activity declines significantly with age does not permit such an examination. We identified an extensive population of young to middle-aged adults who report maintained physical activity levels. This population is employees of the Deutsche Bahn, the national railway company of Germany, rated 163 of the international Fortune 500 Companies in 2009 (CNNMoney.com, 2009).

\section{Research questions}

The aim of present study is two-fold. First, we aim to identify age-specific patterns in the processes by which individuals sustain health behaviour, specifically regular physical activity. In particular, we examine the extent to which planning mediates the relationship of intention to exercise with actual physical activity. We hypothesise that the extent to which planning mediates the intention-behaviour relationship increases with age, due to growing strength of relationship of planning to physical activity with increasing age. Second, we aim to examine possible psychological mechanisms that underlie age differences in the planning-activity link. We test whether increasing strength of relationship of planning to physical activity as age increases can be explained through an increase in use of SOC strategies that result in increased physical activity.

From a statistical perspective, the first aim involves the examination of moderated mediation (Preacher, Rucker, \& Hayes, 2007). Age is hypothesised to moderate (or modify) the mediational path from intention to planning to physical activity by increasing the strength of the link from planning to activity, as manifested in the age $\times$ planning interaction. The second aim involves the examination of mediated moderation (Morgan-Lopez \& MacKinnon, 2006), which characterises the factor that links the age $\times$ planning interaction to physical activity. This factor is hypothesised to be SOC strategy use.

\section{Method \\ Participants and procedure}

Participants were recruited from Germany's national railway company during a routine medical check-up. Employees in security-relevant domains such as engine drivers or track workers receive the same standard of preventive health care and are encouraged to engage in activities that maintain health. After giving informed consent, $N=537$ participants $(83.6 \%$ men) were assessed at baseline (Time 1$)$. Of those, $N=265(49.4 \%)$ returned Time 2 questionnaires (1 month after first assessment). Mean age was 44.9 years $(S D=7.69)$, ranging from 19 to 64 years. The initial sample had a lower education than the German population $(9.9 \%$ vs. $21.6 \%$ with an university entrance degree) and included more men $(83.6 \%$ vs. $48.9 \%$ ). Whereas $21.6 \%$ of the present sample meets the recommendation of spending more than half an hour on moderate or vigorous physical activity at least three times per week, only $13 \%$ in the general population do so (Mensink, 2003). However, the aim of this study was to recruit a mainly blue-collar sample with highly physical strenuous work tasks which may increase the risk of poor physical functioning later in life (Leino-Arjas et al., 2004) and may be prevented by leisure time physical activity (van Eijsden-Besseling et al., 2008). Furthermore, this segment 
of the population is typically underresearched, as studies often involve samples with a higher educational level.

\section{Measures}

All items were taken from Ziegelmann and Lippke (2007) and adapted for the current setting if not stated differently. Behavioural intention was assessed at Times 1 and 2: 'I intend to perform strenuous physical activity (i.e. with an increased heart rate and sweating) in my leisure-time' (Lippke, Ziegelmann, Schwarzer, \& Velicer, 2009). Planning was measured at Times 1 and 2: 'I have already precisely planned, when, where and how to be physically active' (action planning) and 'I have already precisely planned, how I can be physically active even in the face of difficulties and barriers' (coping planning; $r=0.73$ ). The scale $S O C$ strategy use was adapted by Ziegelmann and Lippke (2007) from the original generic questionnaire of SOC strategies (Freund \& Baltes, 2002) to assess self-reported strategy use in the domain of physical activity. For the present study, this domain-specific scale was adapted for leading a healthy lifestyle (Cronbach's $\alpha=0.85$ ). The stem 'Concerning my healthy lifestyle...,' was followed by two items '... I have defined my goals exactly and stick to them' (elective selection) and '... I do everything possible to make my plans to lead a healthy lifestyle come true' (optimisation). The second pair of items consisted of the stem 'When it is getting more difficult to lead a healthy lifestyle...' which was followed by '... I only strive for my most important health goal' (loss-based selection) and '... I increase my efforts even more' (compensation). All items were answered on four-point scales ranging from completely disagree (1) to completely agree (4).

Physical activity was assessed at Times 1 and 2 by three items. The first item was taken from a modified version of the Godin Leisure-Time Exercise Questionnaire (GLTEQ; Godin \& Shephard, 1985) and addressed time spent engaging in moderate and vigorous activity per week. We categorised the number of minutes per week of strenuous and moderate activity in each activity in four categories $(1=0-29 \mathrm{~min} /$ week; $2=30-89 \mathrm{~min} /$ week; $3=90-149 \mathrm{~min} /$ week; $4=150$ and more $\mathrm{min} / \mathrm{week})$. The second item was worded 'I have performed physical activity and sports for at least 30 minutes per week in my leisure time (e.g. gym and playing soccer) with an increased heart rate and sweating'. The third item stated 'I was physically active due to locomotion (e.g. going to work by bike instead of taking the bus)'. Responses were scored on a four-point scale with less than once (1), at least once, at least three times, at least five times (4) per week regarding the last 4 weeks. The three items were used to compute a composite sum score (Cronbach's $\alpha=0.60$ at T1; $\alpha=0.67$ at T2).

Means, standard deviations and intercorrelations of all variables are displayed in Table 1.

\section{Results \\ Analyses}

In a first step, attrition between Times 1 and 2 data collection was examined in tests of difference between those retained versus lost to follow-up. In a second step, the two main hypotheses were examined in separate path models. Mplus Version 3 (Muthén \& Muthén, 2005) was used for model estimation. Full information maximum likelihood estimation (FIML; Arbuckle, 1996) was employed to derive 
Table 1. Intercorrelations and descriptive statistics for behavioural intention, planning, SOC strategy use, physical activity and age.

\begin{tabular}{|c|c|c|c|c|c|c|c|c|c|}
\hline & 2 & 3 & 4 & 5 & 6 & 7 & Range & $M$ & $\mathrm{SD}$ \\
\hline Intention Time 1 & $0.61 * *$ & $0.44^{* *}$ & $0.29 * *$ & $0.43^{* *}$ & $0.41^{* *}$ & -0.03 & $1-4$ & 2.55 & 1.13 \\
\hline 2. Planning Time 1 & & $0.50^{* *}$ & $0.31^{* *}$ & $0.44^{* *}$ & $0.35^{* *}$ & 0.00 & $1-4$ & 2.49 & 1.06 \\
\hline 3. Planning Time 2 & & & $0.50^{* *}$ & $0.33^{* *}$ & $0.45^{* *}$ & -0.07 & $1-4$ & 2.49 & 0.91 \\
\hline 4. SOC strategy use Time 2 & & & & $0.19^{* *}$ & $0.38^{* *}$ & 0.00 & $1-4$ & 2.63 & 0.64 \\
\hline Physical activity Time 1 & & & & & $0.48^{* *}$ & 0.03 & $1-4$ & 2.35 & 0.80 \\
\hline Physical activity Time 2 & & & & & & -0.04 & $1-4$ & 2.56 & 0.76 \\
\hline Age in years & & & & & & & $19-64$ & 44.9 & 7.69 \\
\hline
\end{tabular}

Note: $* * p<0.01$.

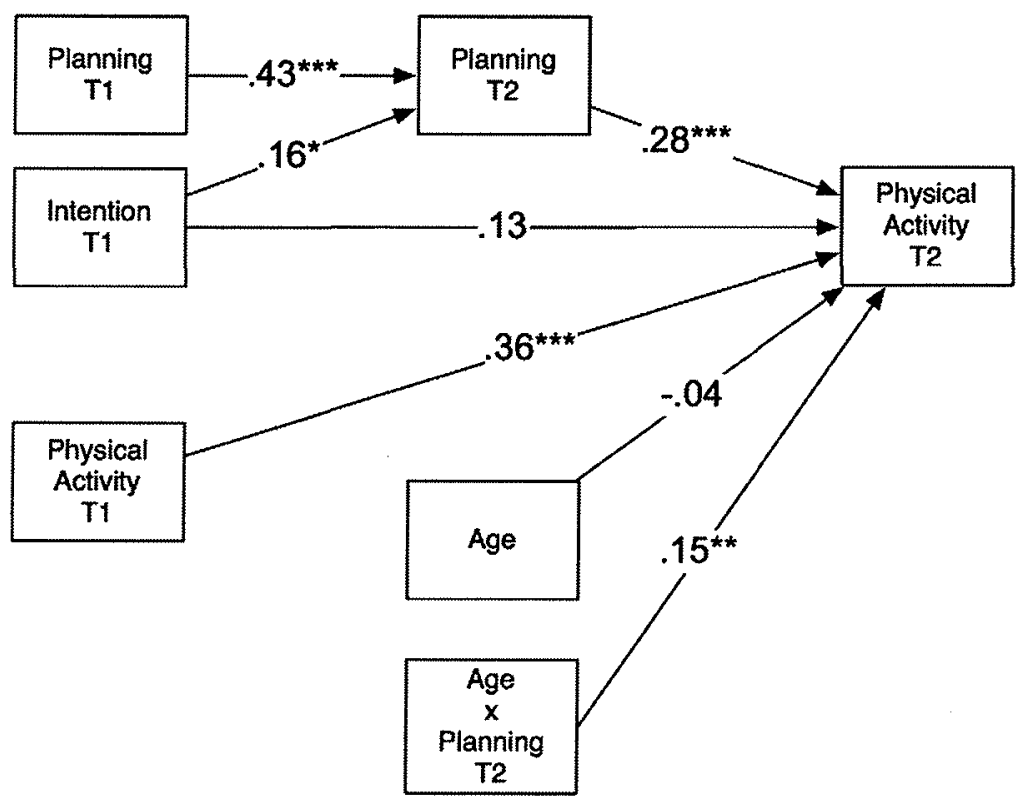

Figure 1. Planning as mediator between behavioural intention and physical activity as a function of age (Note: ${ }^{*} p<0.05,{ }^{* *} p<0.01,{ }^{* * *} p<0.001$; standardised path coefficients are reported).

parameter estimates in the face of missing data; FIML makes use of all available data in model estimation. Given that models involve interactions, predictors were centred into deviation form to render first-order effects interpretable (Aiken \& West, 1991). The first model (Figure 1) included the age $\times$ planning interaction, following the hypothesis that age would moderate the link from intention to physical activity by modifying the path from planning to physical activity (moderated mediation). Following the estimation of Model 1 , the age $\times$ planning interaction was further probed through simple slope analysis (Aiken \& West, 1991) to characterise the relation of planning to physical activity as a function of age. The non-parametric bootstrapping approach of Preacher et al. (2007) was employed to estimate the 


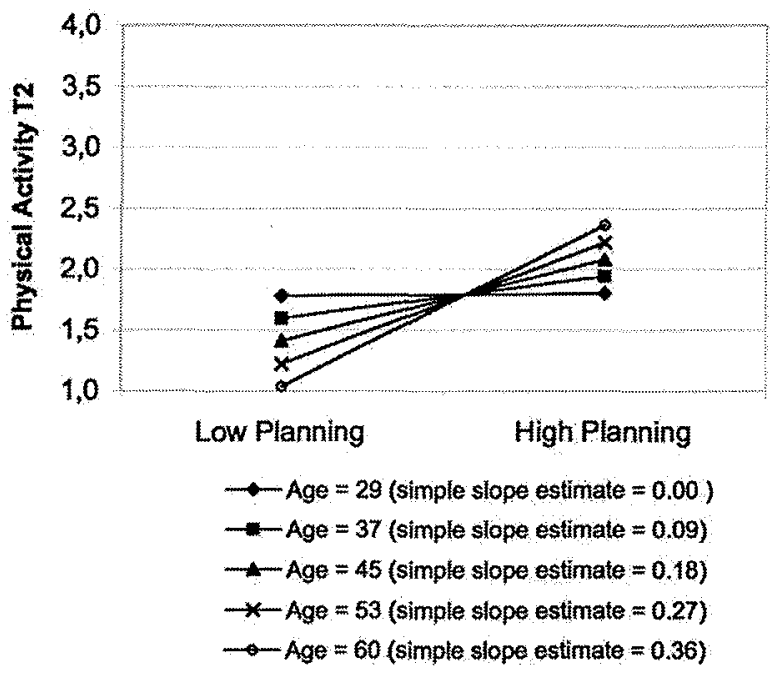

Figure 2. Estimated direct effect of planning on physical activity at different age values.

specific age range through which planning mediated the relationship of intention to physical activity. Put another way, this analysis identified the range of ages in which the indirect effect of intention on physical activity through planning was significant. The second model (Figure 2) tested whether SOC strategy use mediated the relationship of the age by planning interaction to physical activity (mediated moderation). The interaction predicts SOC strategy use which in turn predicts physical activity.

\section{Attrition analysis}

The retention rate of participants from Times 1 to 2 of $49 \%$ is comparable to studies in similar contexts (e.g. Renner, Spivak, Kwon, \& Schwarzer, 2007). We examined differences between those retained versus lost to follow-up on all baseline measures including demographics, physical activity level, intention to engage in physical activity, planning for physical activity and SOC strategy use. No significant differences were found in terms of age, sex, physical activity, behavioural intention and planning. For SOC strategy use a small, albeit statistically significant, difference was found $t(488)=2.06, p<0.05$, effect size $d=0.19$, indicating that those retained reported more SOC strategy use than those lost to follow-up $(M=2.74, S D=0.66$ vs. $M=2.61, S D=0.72$ ).

\section{Age by planning interaction: moderated mediation model}

Estimates of Model 1 are given in Figure 1. The overall model yielded a reasonable fit, $\chi^{2}(2)=7.14 ; p<0.05 ; \mathrm{CFI}=0.97$; RMSEA $=0.08 ; 90 \% \mathrm{CI}=0.03,0.15$.

As shown in Figure 1, planning at $\mathrm{T} 1$ and physical activity at $\mathrm{T} 1$ are included to control for previous levels on these constructs. Intention at Time 1 significantly predicted planning at Time 2 . In turn, planning at Time 2 was significantly associated 
with physical activity Time 2 . The model thus allows estimation of both the direct effect of intention on physical activity and the indirect effect of intention on physical activity through planning $(\beta=0.09 ; S E=0.06 ; 95 \%$-confidence interval from -0.02 to 0.20 ). For correct estimation of the path from the interaction to physical activity, we included a path from age to physical activity (Aiken \& West, 1991). While age did not significantly predict physical activity, the significant positive age by planning interaction predicting physical activity confirmed the first hypothesis, that the relationship of planning to physical activity would increase with age.

\section{Probing the age by planning interaction}

Following Aiken and West (1991) we characterised the age by planning interaction by estimating the regression of physical activity on planning as a function of age. We examined the simple regression of physical activity on planning at five ages: $29,37,45,53$ and 60 years; these ages represent approximate values of the Mean $(M)$ age $-2 \mathrm{SD}, M-1 \mathrm{SD}, M, M+1 \mathrm{SD}$ and $M+2 \mathrm{SD}$, respectively, and tested the significance of the simple slope of physical activity on planning at each age. The estimated simple slope for age $=29$ years $(\beta=0.00$, not significant $)$. At age $=37,45,53$, and 60 years $(\beta=0.09,0.18,0.27$, and 0.36 ) the estimated simple slopes became increasingly positive and statistically significant (all $p$ 's $<0.001$ ), as shown in Figure 2. The cross-over nature of the interaction is critical; at low levels of planning, physical activity appeared to decrease with increasing age, while at high levels of planning, the reverse was true. This cross-over interaction accounts for the lack of overall correlation between age and physical activity, but the significant impact of age is on the planning to behaviour link. In a next step, the conditional indirect effect of intention on physical activity through planning was estimated for the entire age range of the sample using a non-parametric bootstrapping approach ${ }^{1}$ (Preacher et al., 2007). The indirect effect of intention on physical activity through planning was significant $(p<0.05)$ from age 34 to 64 years (the age of the oldest participant). Otherwise stated, planning was found to mediate the intentionbehaviour relation for this age range.

\section{SOC strategy use as a mediator of the age-differential effect on physical activity}

To examine potential underlying mechanisms of the age-differential mediation patterns, SOC strategy use was integrated as a mediator of the relationship of the age by planning interaction to physical activity (Figure 3). Paths from planning and age to SOC were included as required for accurate estimation of the path from the interaction to SOC (Aiken \& West, 1991). Overall model fit was good, $\chi^{2}(3)=0.74 ; p=0.87$; CFI $=1.00$; RMSEA $<0.01 ; 90 \% \mathrm{CI}=0.00,0.05$. Planning at Time 2 significantly predicted SOC strategy use at Time 2 , with planning at Time 1 controlled. The age by planning interaction was significantly associated with SOC strategy use. In turn, SOC strategy use predicted physical activity. The indirect effect from the age by planning interaction to physical activity via SOC strategy use resulted in an indirect effect of $\beta=0.04(\mathrm{SE}=0.02)$. Thus, the age by planning interaction effect on physical activity was partially mediated by SOC strategy use. 


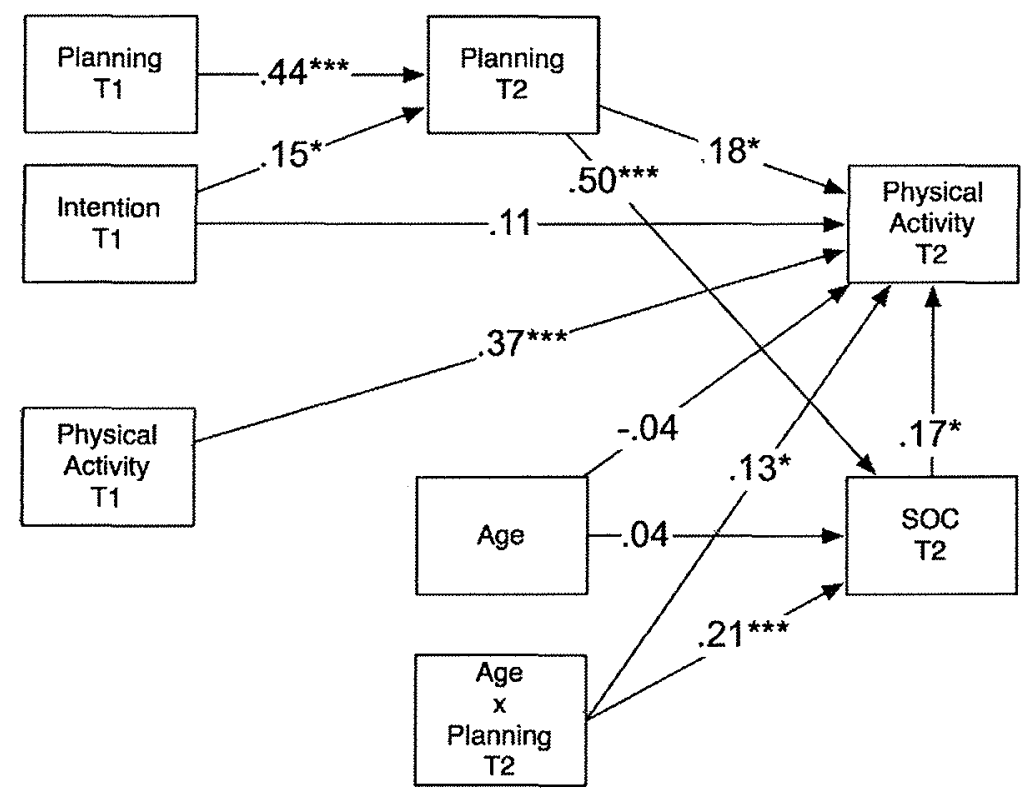

Figure 3. SOC strategy use as mediator of the planning by age interaction effect on physical activity (Note: ${ }^{*} p<0.05,{ }^{* * *} p<0.001$; standardised path coefficients are reported).

\section{Discussion}

The primary goal of this study was to examine the age-differential association patterns between intentions, planning and physical activity in young and middleaged adults and to add a developmental perspective to health behaviour research. Previous studies have found that planning is beneficial for the translation of intentions into behaviour in all adult age groups (Scholz, Sniehotta, Burkert, \& Schwarzer, 2007; Ziegelmann et al., 2006a). However, both studies were conducted in rehabilitation settings. The present study found in a healthy working population that the degree to which planning mediates the intentionbehaviour relation increases with age. In a moderated mediation approach, we probed the conditional indirect effect of intention on physical activity through planning for the entire age range of the sample (19-64 years). The indirect effect increased in size with growing age and was found to be significant only at the age of 34 years and above. Therefore, planning as a way to translate intentions into physical activity seems to be more beneficial for middle-aged than for younger adults. This is in line with the finding that in individuals with a limited future time perspective, the relationship between intention and behaviour was mediated by planning to a greater extent than in those with a more expansive time perspective (Ziegelmann, Lippke, \& Schwarzer, 2006b). Thus, the use of planning to translate goals into behaviour seems to be an adaptive strategy for older individuals or those who perceive their available future time as limited. From a life span developmental perspective, age can be considered a moderator in the self-regulatory framework rather than a direct determinant of health behaviour (cf. Leventhal, Leventhal, \& Schaefer, 1991). 
Strategy use that includes SOC was hypothesised and tested as an intervening explanatory variable for the age by planning interaction for the following reasons: knowledge and use of SOC-related strategies is refined with increasing age (Freund \& Baltes, 2002) and the enactment of plans requires the use of such strategies (Smith, Dixon, \& Baltes, 1989; Ziegelmann et al., 2006a). The inclusion of SOC strategy use revealed that the interaction effect of age and planning on behaviour is partially mediated by using strategies of SOC. This result can be interpreted as indicating that middle-aged adults compared to young adults are more successful in translating their plans into behaviour due to SOC strategy use. For instance, older adults enact their plans and thus achieve their health goals despite barriers by increasing their effort or selecting their most important health goal. The present study is one of the first to examine explanatory variables for the moderating effects of age in behavioural self-regulation.

A different pathway by which planning might affect the intention-behaviour relationship as a function of age is the subjective relevance of the behavioural domain. With increasing age, the personal relevance of health increases (Hooker \& Kaus, 1994), which might explain why in older individuals health-related plans are translated into behaviour more effectively than in younger participants. Additionally, a shift in goal orientation from growth in young adults to maintenance and loss prevention in middle-aged and older adults (Ebner, Freund, \& Baltes, 2006) might serve as an explanatory variable for age differences in goal striving.

Planning might also support behaviour enactment as a mnemonic technique to overcome age-related cognitive problems. Remembering to perform an intended behaviour is an instance of prospective memory (Einstein \& McDaniel, 1990) which has been shown to be subject to age-related decline (Brown \& Park, 2003). Gollwitzer (1999) argues that mentally linking the intended behaviour to situational cues - in terms of when and where - elicits the behaviour almost automatically once the situation is encountered. Therefore, planning might be a strategy to overcome these age-related inhibitions in memory performance.

Further research is needed to explain age-differential self-regulation of health behaviours. Especially, individuals in older age should be included into studies in the future. Additionally, further subgroups of people and contexts may be identified to explain how intentions are differentially translated into behaviour through planning. For instance, the mediating effect of planning between intentions and behaviour has been found to increase with the strength of intention (Wiedemann, Schüz, Sniehotta, Scholz, \& Schwarzer, 2009). Moreover, moderators can influence the mediation process in different ways, e.g. by (1) moderating the intention-planning association, (2) the planning-behaviour association, (3) or both. In the present study, we examined how age moderates the planning-behaviour association. Further research needs to identify other critical variables that modify the link from planning to behaviour and thus to extend our understanding of the mechanisms of health behaviour change in different contexts and for different behaviours.

There are limitations to the present study. The longitudinal, but nonexperimental design of the study does not allow strong inferences for cause-andeffect relationships. The underlying mediation model of the study was based on theoretical consideration and time lag. However, even though observational studies do not allow strong causal inferences, they can provide insights for experimental studies in which the putative causal processes are manipulated (MacKinnon, 
Lockwood, Hoffman, West, \& Sheets, 2002). An experimental-causal-chain design may be employed to test mediation hypotheses experimentally (e.g. Reuter et al., 2008). Further studies are needed, in which planning and SOC strategies are experimentally induced in different age groups to understand age differences and putative explanatory variables.

Data on physical activity were self-reported and thus might be biased. However, in a meta-analysis of 147 studies, Prince et al. (2008) report an average correlation of 0.47 between self-reported physical activity and direct measures of activity (e.g. doubly labelled water, accelerometry). Among male participants there was no systematic bias to either over- or underestimation of physical activity relative to direct measures. Finally, regarding the reported age-related findings, one has to bear in mind that cross-sectional age data are unable to unconfound chronological age, cohort and selective mortality.

\section{Conclusions}

The pursuit of health-related goals requires self-regulation strategies such as planning the intended behaviour. While previous research has demonstrated that planning mediates the intention-behaviour relation (e.g. Norman \& Conner, 2005; Schwarzer et al., 2008), the present study provides to our knowledge the first evidence for an increased association of planning and goal attainment with increasing age. As a first attempt to explore age-differential mediation patterns when intentions are translated into behaviour through planning, the present study compared young and middle-aged adults. Furthermore, SOC strategy use was examined as an explanatory variable for age differences. These findings might be helpful for stimulating further research on volitional processes of health behaviour change and, in particular, conditional mediation effects of the intention-behaviour association. Furthermore, the present findings may be useful for designing effective age-specific interventions. Increasing strategy knowledge and training of successful planning seems to be a promising domain of intervention for increasing physical activity in older age groups. In our moderated mediation approach, we have found in individuals among a working population that planning as a way to translate intentions into physical activity seems to be more beneficial for middle-aged (34-64 years) than for younger adults (19-33 years). Furthermore, as SOC strategy use was found to be an explanatory variable for these age differences, we speculate that a SOC strategy training would be of particular benefit in interventions targeting middle-aged adults. This particular age range can be approached for health-related interventions in worksite settings. Future research is needed to replicate the findings in nonworking populations and also needs to examine the interplay of intention, planning, SOC strategy use and behaviour in individuals above the age of 64 years, which represents the age groups of the youngest old and the oldest old.

\section{Acknowledgements}

The authors would like to thank the Deutsche Bahn AG and its employees for participating in this study. During the work on her dissertation, T. Reuter was a pre-doctoral fellow of the International Max Planck Research School 'The Life Course: Evolutionary and Ontogenetic Dynamics' (LIFE, www.imprs-life.mpg.de). This work has been supported by the German 
Ministry of Education and Research (BMBF) within the project FLARE-BSA (Project ID 01 ET0801). The content is the sole responsability of the authors.

\section{Note}

1. Non-parametric bootstrapping was used for estimating the sampling distribution of the indirect effect as a function of age. The percentile-based confidence intervals were further improved through bias-correction and acceleration (Preacher et al., 2007). The results verified the results of the normal-theory approach for assessing the indirect effect moderated by age.

\section{References}

Abraham, C., Sheeran, P., \& Johnston, M. (1998). From health beliefs to self-regulation: Theoretical advances in the psychology of action control. Psychology \& Health, 13, 569-591.

Aiken, L.S., \& West, S.G. (1991). Multiple regression: Testing and interpreting interactions. Thousand Oaks: Sage.

Aldwin, C.M., Spiro III, A., Park, C.L., Birren, J.E., \& Schaie, K.W. (2006). Health, behavior, and optimal aging: A life span developmental perspective. Handbook of the psychology of aging (6th ed., pp. 85-104). Amsterdam, Netherlands: Elsevier.

Arbuckle, J.L. (1996). Full information estimation in the presence of incomplete data. In G.A. Marcoulides, \& R.E. Schumacker (Eds.), Advanced structural equation modeling (pp. 243-277). Mahwah, NJ: Erlbaum.

Armitage, C.J. (2007). Effects of an implementation intention-based intervention on fruit consumption. Psychology \& Health, 22, 917-928.

Baltes, P.B., \& Baltes, M.M. (1990). Psychological perspectives on successful aging: The model of selective optimization with compensation. In P.B. Baltes, \& M.M. Baltes (Eds.), Successful aging: Perspectives from the behavioral sciences (pp. 1-34). New York: Cambridge University Press.

Baltes, P.B., \& Smith, J. (2003). New frontiers in the future of aging: From successful aging of the young old to the dilemmas of the fourth age. Gerontology, 49, 123-135.

Bijnen, F.C.H., Feskens, E.J.M., Caspersen, C.J., Mosterd, W.L., \& Kromhout, D. (1998). Age, period, and cohort effects on physical activity among elderly men during 10 years of follow-up: The Zutphen elderly study. Journals of Gerontology: Biological Sciences and Medical Sciences, 53A, 235-241.

Blair, S.N., \& LaMonte, M.J. (2006). Physical activity, fitness, and mortality rates. In C. Bouchard, S.N. Blair, \& W.L. Haskell (Eds.), Physical Activity and Health (pp. 143-159). Champaign, IL: Human Kinetics.

Brown, S.C., \& Park, D.C. (2003). Theoretical models of cognitive aging and implications for translational research in medicine. The Gerontologist, 43, 57-67.

CNNMoney.com (2008). Global 500: Our ranking of the world's largest corporations (July 21 last update). Retrieved February 11, 2009, from http://money.cnn.com/magazines/ fortune/global500/2008/full_list/101_200.html.

Das, J.P., Kar, B.C., \& Parrila, R.K. (1996). Cognitive planning: The psychological basis of intelligent behavior. New Delhi, India: Sage.

Ebner, N.C., Freund, A.M., \& Baltes, P.B. (2006). Developmental changes in personal goal orientation from young to late adulthood: From striving for gains to maintenance and prevention of losses. Psychology and Aging, 21, 664-678.

Einstein, G.O., \& McDaniel, M.A. (1990). Normal aging and prospective memory. Journal of Experimental Psychology: Learning, Memory, and Cognition, 16, 717-726. 
Freund, A.M., \& Baltes, P.B. (2000). The orchestration of selection, optimization, and compensation: An action-theoretical conceptualization of a theory of developmental regulation. In W.J. Perrig, \& A. Grob (Eds.), Control of human behavior, mental processes and consciousness (pp. 35-58). Mahwah, NJ: Erlbaum.

Freund, A.M., \& Baltes, P.B. (2002). Life-management strategies of selection, optimization and compensation: Measurement by self-report and construct validity. Journal of Personality and Social Psychology, 82, 642-662.

Godin, G., \& Shephard, R.J. (1985). A simple method to assess exercise behavior in the community. Canadian Journal of Applied Sport Sciences, 10, 141-146.

Gollwitzer, P.M. (1999). Implementation intentions: Strong effects of simple plans. American Psychologist, 54, 493-503.

Gollwitzer, P.M., \& Oettingen, G. (1998). The emergence and implementation of health goals. Psychology \& Health, 13, 687-715.

Heckhausen, H., \& Gollwitzer, P.M. (1987). Thought contents and cognitive functioning in motivational vs. volitional states of mind. Motivation \& Emotion, 11, 101-120.

Hooker, K., \& Kaus, C.R. (1994). Health-related possible selves in young and middle adulthood. Psychology and Aging, 9, 126-133.

Hu, G., Tuomilehto, J., Silventoinen, K., Barengo, N.C., Peltonen, M., \& Jousilahti, P. (2005). The effects of physical activity and body mass index on cardiovascular, cancer and allcause mortality among 47212 middle-aged Finnish men and women. International Journal of Obesity, 29, 894 902.

Leino-Arjas, P., Solovieva, S., Riihimäki, H., Kirjonen, J., \& Telama, R. (2004). Leisure time physical activity and strenuousness of work as predictors of physical functioning: A 28 year follow up of a cohort of industrial employees. Occupational and Environmental Medicine, 61, 1032-1038.

Leventhal, H., Leventhal, E.A., \& Schaefer, P. (1991). Vigilant coping and health behavior: A life span problem. In M. Ory, \& R. Abeles (Eds.), Aging, Health, and Behavior (pp. 109-140). Baltimore: Johns Hopkins.

Lippke, S., Ziegelmann, J.P., Schwarzer, R., \& Velicer, W.F. (2009). Validity of stage assessment in the adoption and maintenance of physical activity and fruit and vegetable consumption. Health Psychology, 28, 183-193.

MacKinnon, D.P., Lockwood, C.M., Hoffman, J.M., West, S.G., \& Sheets, V. (2002). A comparison of methods to test mediation and other intervening variable effects. Psychological Methods, 7, 83-104.

McAuley, E., \& Rudolf, D. (1995). Physical activity, aging, and psychological well-being. Journal of Aging and Physical Activity, 3, 67-96.

Mensink, G.B.M. (2003). Bundes-Gesundheitssurvey: Körperliche Aktivität. Gesundheitsberichterstattung des Bundes (Federal health survey: Physical activity. Health report of the Federal Republic of Germany). Berlin: Robert Koch-Institut.

Morgan-Lopez, A.A., \& MacKinnon, D.P. (2006). Demonstration and evaluation of a method for assessing mediated moderation. Behavior Research Methods, 38, 77-87.

Muthén, L.K., \& Muthén, B.O. (2005). MPlus user's guide - 3rd edition. Los Angeles, CA: Muthén \& Muthén.

Norman, P., \& Conner, M. (2005). The theory of planned behavior and exercise: Evidence for the mediating and moderating roles of planning on intention-behavior relationships. Journal of Sport \& Exercise Psychology, 27, 488-504.

Pham, L.B., \& Taylor, S.E. (1999). From thought to action: Effects of process- versus outcome-based mental simulations on performance. Personality and Social Psychology Bulletin, 25, 250-260.

Preacher, K.J., Rucker, D.D., \& Hayes, A.F. (2007). Addressing moderated mediation hypotheses: Theory, methods, and prescriptions. Multivariate Behavioral Research, 42, $185-227$ 
Prince, S.A., Adamo, K.B., Hamel, M.E., Hardt, J., Gorber, S.C., \& Tremblay, M. (2008). A comparison of direct versus self-report measures for assessing physical activity in adults: A systematic review. International Journal of Behavioral Nutrition and Physical Activity. 5:56. DOI:10.1186/1479-5868-5-56.

Prohaska, T.R., \& Clark, M.A. (1997). Health behavior and the human life cycle. In D.S. Gochman (Ed.), Handbook of health behavior research III: Demography, development and diversity (pp. 29-48). New York: Plenum Press.

Renner, B., Spivak, Y., Kwon, S., \& Schwarzer, R. (2007). Does age make a difference? Predicting physical activity of South Koreans. Psychology and Aging, 22, 482-493.

Reuter, T., Ziegelmann, J.P., Wiedemann, A.U., \& Lippke, S. (2008). Dietary planning as a mediator of the intention-behavior relation: An experimental-causal-chain design. Applied Psychology: An International Review. Special Issue: Health and Well-Being, 57, 194-207.

Schaie, K.W. (1988). Ageism in psychological research. American Psychologist, 43, 179-183.

Scholz, U., Sniehotta, F.F., Burkert, S., \& Schwarzer, R. (2007). Increasing physical exercise levels: Age-specific benefits of planning. Journal of Aging and Health, 19, 851-866.

Schwarzer, R., Luszczynska, A., Ziegelmann, J.P., Scholz, U., \& Lippke, S. (2008). Socialcognitive predictors of physical exercise adherence: Three longitudinal studies in rehabilitation. Health Psychology, 27, 854-863.

Sheeran, P. (2002). Intention-behavior relations: A conceptual and empirical review. European Review of Social Psychology, 12, 1-36.

Smith, J., Dixon, R.A., \& Baltes, P.B. (1989). Expertise in life-planning: A new research approach to investigating aspects of wisdom. In M.L. Commons, J.D. Sinnott, F.A. Richards, \& C. Armon (Eds.), Beyond formal operations II (Vol. 1, pp. 307-331). New York: Praeger.

Sniehotta, F.F., Scholz, U., \& Schwarzer, R. (2005). Bridging the intention-behaviour gap: Planning, self-efficacy, and action control in the adoption and maintenance of physical exercise. Psychology \& Health, 20, 143-160.

Sniehotta, F.F., Scholz, U., \& Schwarzer, R. (2006). Action plans and coping plans for physical exercise: A longitudinal intervention study in cardiac rehabilitation. British Journal of Health Psychology, 11, 23-37.

van Eijsden-Besseling, M.D., Staal, J.B., van Attekum, A., de Bie, R.A., \& van den Heuvel, W.J. (2008). No difference between postural exercises and strength and fitness exercises for early, non-specific, work-related upper limb disorders in visual display unit workers: A randomised trial. Australian Journal of Physiotherapy, 54, 95-101.

Verbrugge, L.M., Gruber-Baldini, A.L., \& Fozard, J.L. (1996). Age differences and age changes in activities: Baltimore Longitudinal Study of Aging. Journals of Gerontology: Psychological Sciences and Social Sciences, 51B, 30-41.

Webb, T.L., \& Sheeran, P. (2007). How do implementation intentions promote goal attainment? A test of component processes. Journal of Experimental Social Psychology, 43, 295-302.

Wiedemann, A.U., Schüz, B., Sniehotta, F.F., Scholz, U., \& Schwarzer, R. (2009). Disentangling the relation between intentions, planning, and behaviour: A moderated mediation analysis. Psychology \& Health, 24, 67-79.

Ziegelmann, J.P., \& Lippke, S. (2007). Planning and strategy use in health behavior change: A life span view. International Journal of Behavioral Medicine, 14, 30-39.

Ziegelmann, J.P., Lippke, S., \& Schwarzer, R. (2006a). Adoption and maintenance of physical activity: Planning interventions in young, middle-aged, and older adults. Psychology \& Health, 21, 145-163.

Ziegelmann, J.P., Lippke, S., \& Schwarzer, R. (2006b). Subjective residual life expectancy in health self-regulation. Journals of Gerontology: Psychological Sciences, 61B, 195-201.

Ziegelmann, J.P., Luszczynska, A., Lippke, S., \& Schwarzer, R. (2007). Are goal intentions or implementation intentions better predictors of health behavior? A longitudinal study in orthopedic rehabilitation. Rehabilitation Psychology, 52, 97-102. 